九州大学学術情報リポジトリ

Kyushu University Institutional Repository

\title{
Study of Tip Deflection on a Copper-Steel bimetallic Strip by Fuzzy Logic and ANSYS Static Structural
}

Muhammad Talha Khan

Government Islamia College Civil Lines

Muhammad Javaid Afzal

Government Islamia College Civil Lines

Javaid, Farah

Govt. APWA College (W) Lahore

Tayyaba, Shahzadi

The University of Lahore

他

https://doi.org/10.5109/4738596

出版情報: Proceedings of International Exchange and Innovation Conference on Engineering \& Sciences (IEICES). 7, pp. 255-260，2021-10-21. 九州大学大学院総合理工学府 バージョン:

権利関係 : 


\title{
Study of Tip Deflection on a Copper-Steel bimetallic Strip by Fuzzy Logic and ANSYS Static Structural
}

\author{
Muhammad Talha Khan ${ }^{1}$, Muhammad Javaid Afzal ${ }^{*}$, Farah Javaid ${ }^{2}$, Shahzadi Tayyaba ${ }^{3}$, Muhammad Waseem Ashraf ${ }^{4}$, \\ Md. Khalid Hossain ${ }^{5,6}$ \\ ${ }^{1}$ Government Islamia College Civil Lines, Lahore, Pakistan, \\ ${ }^{2}$ Govt. APWA College (W) Lahore, Pakistan, \\ ${ }^{3}$ The University of Lahore, Pakistan, \\ ${ }^{4}$ G.C. University Lahore, Pakistan, \\ ${ }^{5}$ Kyushu University, Fukuoka, 816-8580, Japan. \\ ${ }^{6}$ Bangladesh Atomic Energy Commission, Dhaka, 1349, Bangladesh. \\ *Corresponding author email: javaidphy@gmail.com
}

\begin{abstract}
Steel and copper are the most widely used materials around the world. In this work, the tip deflection of a fixedfree support Copper-Steel bimetallic strip is simulated using Fuzzy Logic and ANSYS Static Structural. Copper-steel is a very popular bimetal and is used widely in different fields of technology. For Fuzzy simulation, Tip Deflection Fuzzy Logic Controller (TDFLC) is designed with three inputs as T.Diff, Thickness, and Length while T.Deflection as output. For input values of T.Diff $\left(278^{\circ} \mathrm{C}\right)$, thickness $(1.4 \mathrm{~mm})$ and length $(120 \mathrm{~mm})$ TDFLC generates T.Deflection of $12.8 \mathrm{~mm}$ with an error of $1.59 \%$. For real-time simulation, the geometry of dimension $120 \times 7 \times 1.4 \mathrm{~mm}$ is designed by ANSYS. At the temperature difference of $278{ }^{\circ} \mathrm{C}$, ANSYS results are $12.8 \mathrm{~mm}$ with an error of $1.59 \%$. The results concluded that the tip deflection is inversely related to thickness while in direct relation with both temperature difference and Length of bimetal.
\end{abstract}

Keywords: Copper-Steel; Bimetal; Tip deflection; Bimetallic strip; Fuzzy Logic Controller

\section{INTRODUCTION}

Steel and copper are the most widely used materials around the world. With the advancement in science and technology, individual materials or single alloys are not enough to meet the requirements of engineering and industry. Bimetals are an excellent replacement for individual materials. Bimetals are composed of two different materials with different physical and chemical properties. Thus, they not only reduce the weaknesses of the individual materials but also are cost-effective and have more additional properties. Copper-steel is a very popular bimetal and is used widely in different fields of technology. Copper-steel bimetals are commonly used in industry and engineering fields as pipeline tubes, bimetallic sheets, wires, bearing brushes, and other components of engineering machines [1]. As lead is harmful to both human health and the environment, so its use is decreasing day by day. Copper-steel bimetal is also an excellent replacement for lead [2,3].

Bimetals are composites comprise of two layers of different materials with different coefficients of thermal expansion [4]. Bimetal beams are highly sensitive to thermal conditions and bend with temperature changes. The least value of heat change that a bimetallic cantilever can detect lies in the range of femtojoule [5]. This bimetallic effect is based on S. Timoshenko's theory of bimetallic strip thermostats [6]. When a bimetallic beam observes the temperature change, the layer with higher C.T.E or active layer tends to elongate more than the layer with lower C.T.E or passive layer. This causes tension in the passive while compression in the active layer. Due to these compression and tension forces, bimetal tend to bend toward the passive layer [7].
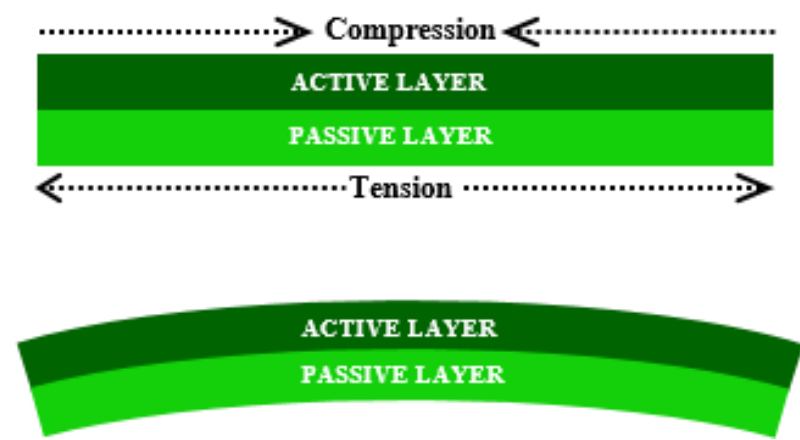

Fig. 1. Bimetallic effect in Bimetallic beam

Bimetals with one end fixed to support and the other end free to move are also used in electric switches for avoiding over-currents (7). For a fixed free end bimetal beam the tip deflection can be calculated by the formula

$$
\delta=\frac{f \Delta T L^{2}}{h}
$$

Where $\delta$ is tip deflection, $\Delta T$ is the temperature difference, $L$ is the length of beam and $f$ is the specific deflection of the bimetal composites. Specific deflection depends on the materials used for making bimetal and the ratio of the thickness of the individual layers of the bimetal. Specific deflection of the bimetal composite can be measured by using the formula

$$
f=\frac{1}{2}\left(\frac{6\left(\alpha_{2}-\alpha_{1}\right)(1+m)^{2}}{3(1+m)^{2}+(1+m \cdot n)\left(m^{2}+\frac{1}{m \cdot n}\right)}\right)
$$

Where $\alpha_{2}-\alpha_{1}$ is the difference between coefficients of thermal expansion of bimetal materials, $m$ is the ratio of the thickness of the individual layers of the bimetal, and $\mathrm{n}$ is the ratio of the young modulus of the individual layers of the bimetal [8]. 


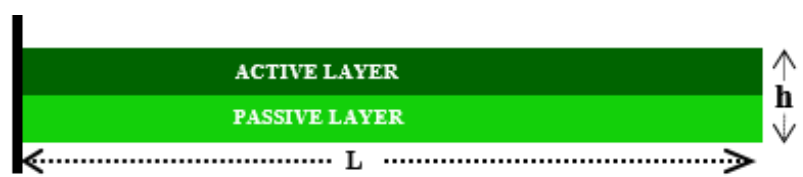

Fig. 2. Fixed-free support bimetallic beam

Different scientists and researchers used bimetals in capacitors. The gap produced between the layers of capacitors due to the thermal deflection of bimetals can be used for auto-tuning of the capacitance of capacitors [9, 10]. In 1993, W. H. Chu et al proposed a model relating the tip deflection of bimetallic cantilever microactuator with temperature change. The results of the model were compared with Finite Element Analysis results. The presented model produced results with accuracy better than $10 \%$ [11]. In 2011, M. A. Ismail et al. used Fiber Bragg Grating (FBG) Bimetalas a temperature sensor to measure the temperature of solar panels. This (FBG) bimetal temperature sensor has maximum sensitivity between 41 to $90^{\circ} \mathrm{C}$ [12].In 2012, A. V. Rao et al. used Finite Element Analysis to develop an empirical formula to calculate the thermal deformation of a bimetallic beam under the change in temperature. The results concluded that thermal deformation of the bimetallic beam is linearly related to change in temperature[13]. In 2020, Z. Zhang et al. used bimetal to steer the configuration of solar panels. The bimetallic effect is used to steer solar panels in such a direction so that solar cells get maximum solar radiation[14].In 2020, M. Kang et al. used free end and fixed-fixed support bimetal beams for the thermal energy harvesting based on combined piezo and pyroelectric effect. This work used small temperature variations with a frequency below $0.1 \mathrm{~Hz}$. The prototype produces a power output of about $0.4 \mu \mathrm{W}$ at a temperature difference of $15 \mathrm{~K}$ [15]. In 2021, R. K. Jaya Kumar et al. compared the electrothermal deflection between Copper-Steel and Aluminium-Steel bimetals composites by using ANSYS. This simulation used the current ranges between 1-32 Amperes. Results concluded that Aluminium-Steel showed more deflection than Copper-Steel bimetal composites [16].In 2021, M. Talha Khan used ANSYS Static Structural to compare the thermal deformation between copper-steel and Aluminium-Steel bimetals. This simulation compared the thermal deformation in bimetals against a temperature range of 22 to $300{ }^{\circ} \mathrm{C}$. At maximum temperature of $300{ }^{\circ} \mathrm{C}$, Copper-Steel showed a thermal deformation of $0.36 \mathrm{~mm}$ and Aluminium-Steel showed thermal deformation of $0.62 \mathrm{~mm}$ [17]. Different scientists and researchers studied the thermal behavior of bimetals and used them in different engineering fields and technology [18-30]. Many scientists have used ANSYS and Fuzzy for their research work for better results [31-42].

\section{FUZZY LOGIC CONTROLLER SIMULATION}

Fuzzy Logic Controller (FLC) is an innovative simulation technique provided by MATLAB. FLC is used to deal with problems in the shade of grey. In this work, Tip Deflection Fuzzy Logic Controller (TDFLC) is designed to observe the tip deflection of a copper-steel bimetallic strip. The TDFLC consists of three input variables as T.Diff, Thickness, and Length while
TDeflection is the output variable. The Fuzzy Inference System (FIS) of TDFLC using the Mamdani model is depicted in the figure.

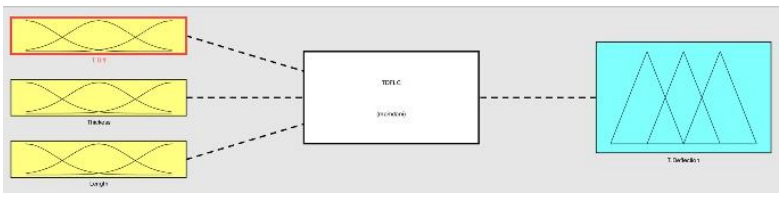

Fig. 3. TDFLC Function Designer

Three membership functions are designed for each TDFLC variable using the membership function editor. The membership functions of T.diff consist of smallT, medium, and highT. The membership functions of Thickness consist of the thick, medium, and thin. The membership functions of Length consist of small, medium, and largeL. The membership functions of output variable TDeflection consist of smallT.D, mediumT.D, and largeT.D. The membership functions of input variables T.diff, Thickness and Length, and output graph of T.D are depicted in Figures 4-7.

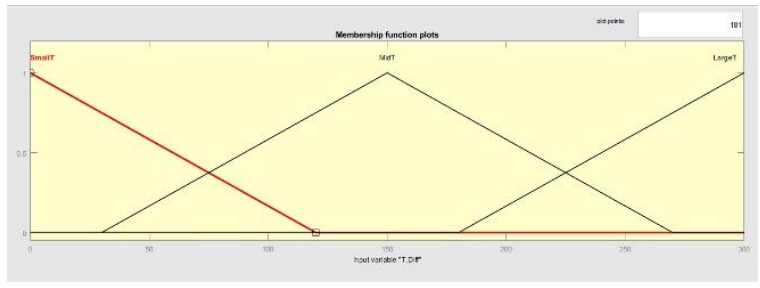

Fig. 4. Membership Function for T.Diff variable

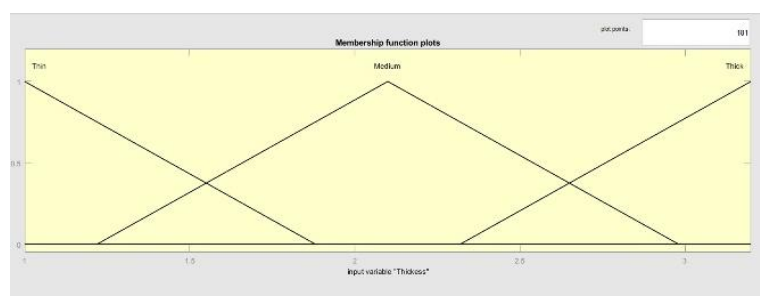

Fig. 5. Membership Function for Thickness variable

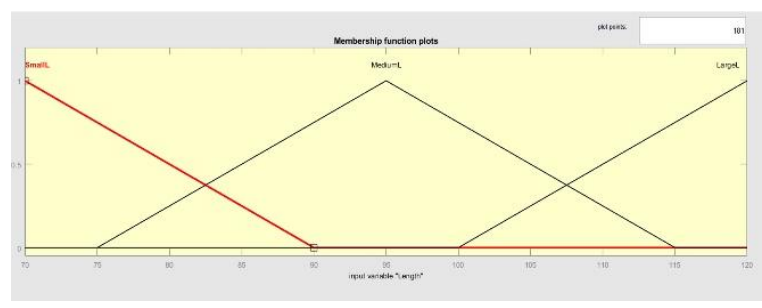

Fig. 6. Membership Function for Length variable

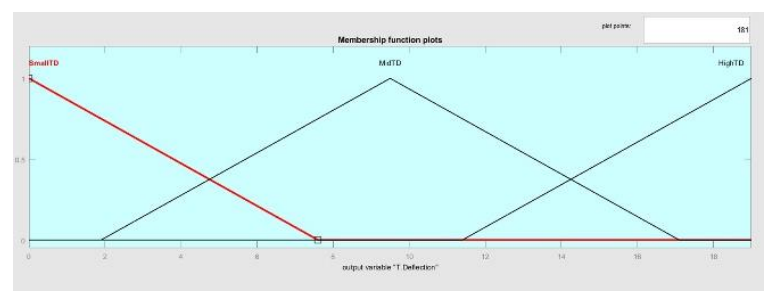

Fig. 7. Membership Function for T.Deflection variable 
TDFLC has three input variables and corresponding three membership functions for each input variable. To observe tip deflection 27 rules are defined using IFAND-THEN logic in the TDFLC rule editor according to the following equation

$$
\text { Number of rules }=m^{n}
$$

Where $m$ and $n$ represent the membership function and number of input variables. Rules for TDFLC are shown in table 1 .

Table 1. Rules for TDFLC

\begin{tabular}{|c|c|c|c|c|}
\hline No. & $\begin{array}{c}\text { T.Diff } \\
\left({ }^{\circ} \mathbf{C}\right)\end{array}$ & $\begin{array}{c}\text { Thickness } \\
(\mathbf{m m})\end{array}$ & $\begin{array}{c}\text { Length } \\
(\mathbf{m m})\end{array}$ & $\begin{array}{c}\text { T.Deflection } \\
\left({ }^{\circ} \mathbf{C}\right)\end{array}$ \\
\hline 1 & SmallT & Thin & SmallL & SmallTD \\
\hline 2 & SmallT & Thin & MediumL & SmallTD \\
\hline 3 & SmallT & Thin & LargeL & SmallTD \\
\hline 4 & SmallT & Medium & SmallL & SmallTD \\
\hline 5 & SmallT & Medium & MediumL & SmallTD \\
\hline 6 & SmallT & Medium & LargeL & SmallTD \\
\hline 7 & SmallT & Thick & SmallL & SmallTD \\
\hline 8 & SmallT & Thick & MediumL & SmallTD \\
\hline 9 & SmallT & Thick & LargeL & SmallTD \\
\hline 10 & MidT & Thin & SmallL & SmallTD \\
\hline 11 & MidT & Thin & MediumL & MidTD \\
\hline 12 & MidT & Thin & LargeL & MidTD \\
\hline 13 & MidT & Medium & SmallL & SmallTD \\
\hline 14 & MidT & Medium & MediumL & SmallTD \\
\hline 15 & MidT & Medium & LargeL & MidTD \\
\hline 16 & MidT & Thick & SmallL & SmallTD \\
\hline 17 & MidT & Thick & MediumL & SmallTD \\
\hline 18 & MidT & Thick & LargeL & SmallTD \\
\hline 19 & LargeT & Thin & SmallL & MidTD \\
\hline 20 & LargeT & Thin & MediumL & MidTD \\
\hline 21 & LargeT & Thin & LargeL & HighTD \\
\hline 22 & LargeT & Medium & SmallL & SmallTD \\
\hline 23 & LargeT & Medium & MediumL & MidTD \\
\hline 24 & LargeT & Medium & LargeL & MidTD \\
\hline 25 & LargeT & Thick & SmallL & SmallTD \\
\hline 26 & LargeT & Thick & MediumL & MidTD \\
\hline 27 & LargeT & Thick & LargeL & MidTD \\
\hline
\end{tabular}

Based on designed membership functions and defined rules TDFLC generates output results for tip deflection. TDFLC Rule viewer shows a crisp value of T.Deflection for specified values of input. For a crisp value of T.Diff to be $278{ }^{\circ} \mathrm{C}$, Thickness to be $1.4 \mathrm{~mm}$ and Length to be $120 \mathrm{~mm}$ TDFLC generate a crisp value of $12.8 \mathrm{~mm}$ for T.Deflection as depicted in the figure

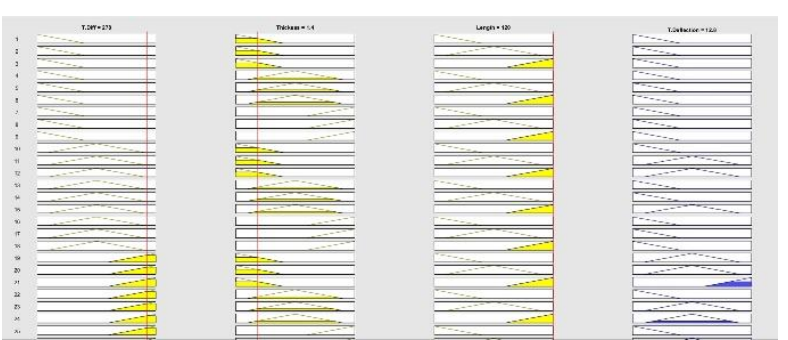

Fig. 8. Rule Viewer TDFLC

The 3-D surface viewer graph with input variables T.Diff, Thickness, and Length and output variable T.D is depicted in fig 9. Fig 9a presents the dependency of T.Deflection on T.Diff and Thickness. Fig 9b presents the dependency of T.D on T.Diff and Length. Fig 9c presents the dependency of T.D on Thickness and Length The TDFLC surface viewer with input variables along $\mathrm{x}$ and $y$-axis while output along the $\mathrm{z}$-axis is depicted in fig

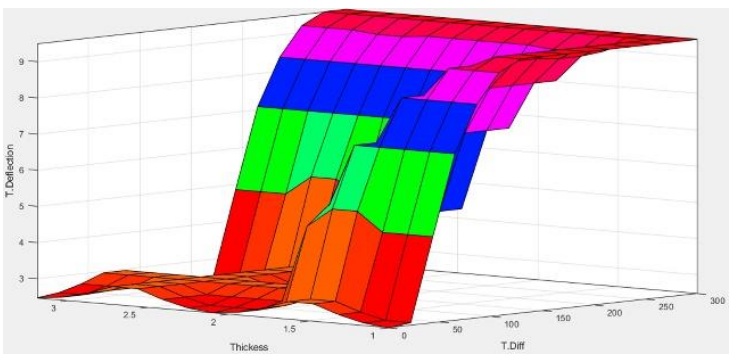

(a)

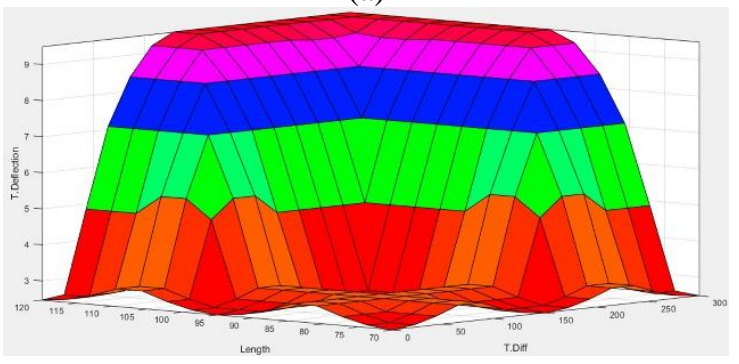

(b)

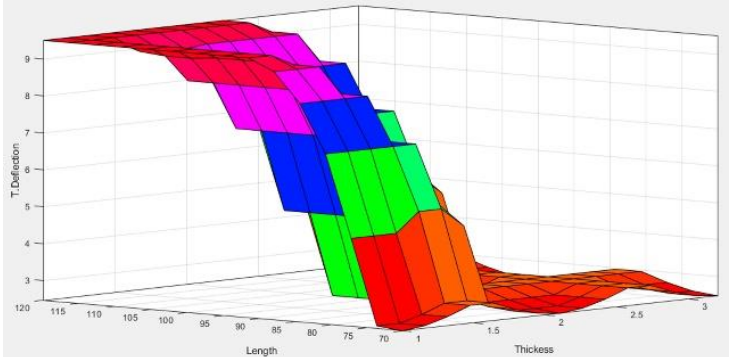

(c)

Fig. 9. 3-D Surface Viewer TDFLC for T.Deflection. Fig. 9a. presents the dependency of T.Deflection on T.Diff and Thickness. Fig. 9b. presents the dependency of T.D on T.Diff and Length. Fig. 9c. presents the dependency of T.D on Thickness and Length.

\section{ANSYS SIMULATION}

ANSYS is a very powerful software for real-time simulations. ANSYS is very popular around the world for multiphysics simulations. In this study, ANSYS Static Structural is used to observe the tip deflection in a Copper-Steel bimetallic strip. The geometry of the bimetallic strip with dimensions of $120 \times 7 \times 1.4 \mathrm{~mm}$ is designed in ANSYS Workbench design modeler as depicted in figure 


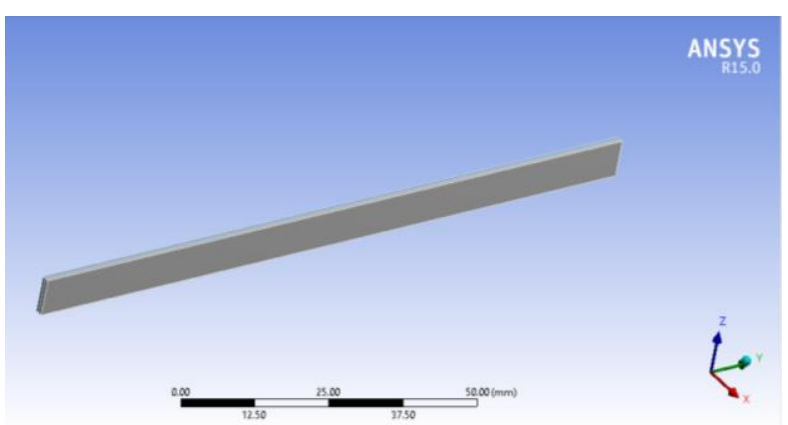

Fig. 10. Modeling of Bimetallic strip

The initial temperature of the bimetallic beam is $22^{\circ} \mathrm{C}$. For real-time simulation, material properties are selected by ANSYS Engineering data source. The material properties with dimensions of an individual layer of the bimetallic strip are shown in table 2 .

Table 2. Material Properties of bimetallic Strip

\begin{tabular}{|l|c|c|}
\hline Parameters & \multicolumn{2}{|c|}{ Material } \\
\hline Length (mm) & 120 & Copper \\
\hline Width (mm) & 7 & 120 \\
\hline Thickness (mm) & 0.7 & 7 \\
\hline $\begin{array}{l}\text { Initial } \\
\text { Temperature } \\
\left({ }^{\circ} \text { C) }\right.\end{array}$ & 22 & 0.7 \\
\hline Density (kgm-1) & $7850[16]$ & $8300[16]$ \\
\hline $\begin{array}{l}\text { Young Modulus } \\
(\text { Pa) }\end{array}$ & $2 \mathrm{E}+11[16]$ & $1.1 \mathrm{E}+11[16]$ \\
\hline Poisson's Ratio & $0.3[16]$ & $0.34[16]$ \\
\hline $\begin{array}{l}\text { Bulk Modulus } \\
(\text { Pa) }\end{array}$ & $1.6667 \mathrm{E}+11$ & $1.1458 \mathrm{E}+11$ \\
\hline $\begin{array}{l}\text { Shear Modulus } \\
(\text { Pa) }\end{array}$ & $7.6923 \mathrm{E}+10$ & $4.1045 \mathrm{E}+10$ \\
\hline $\begin{array}{l}\text { Coefficient of } \\
\text { Thermal } \\
\text { expansion }\left({ }^{\circ} \mathbf{C}^{-1}\right)\end{array}$ & $1.2 \mathrm{E}-05[16]$ & $1.8 \mathrm{E}-05[16]$ \\
\hline
\end{tabular}

For precise simulation, the bimetallic strip geometry has finely meshed with the size of elements set to be $0.7 \mathrm{~mm}$. The meshed setting comprises medium smoothing, coarse relevance center, and coarse span angle center. The meshed geometry is composed of 25906 nodes and 3440 elements in total.

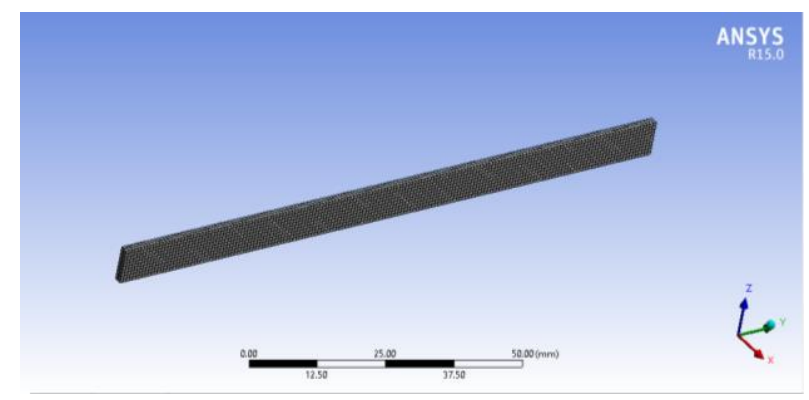

Fig. 11. Meshing of Bimetallic Strip

The thermal condition of $300{ }^{\circ} \mathrm{C}$ is applied on CopperSteel bimetallic strip to observe the thermal deflection on its tip. The initial temperature of the bimetallic strip is $22{ }^{\circ} \mathrm{C}$ with zero tip deflection. When temperature increase, bimetallic strip experience thermal deflection on the tip side of the strip. At $300{ }^{\circ} \mathrm{C}$ temperature, the bimetallic strip shows a tip deflection of $12.8 \mathrm{~mm}$ as depicted in figure 12 .

Fig. 12. Tip Deflection in Copper-Steel bimetallic Strip

\section{RESULTS AND DISCUSSION}

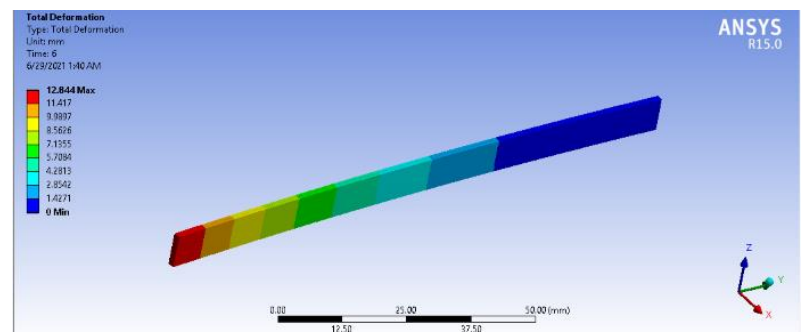

For Fuzzy simulation, Tip Deflection Fuzzy Logic Controller (TDFLC) is designed with three input variables as T.Diff, Thickness, and Length and T.Deflection as output variable. TDFLC Rule Viewer is used to observe the T.Deflection for crisp values of inputs. For a crisp value of T.Diff to be $278{ }^{\circ} \mathrm{C}$, Thickness to be $1.4 \mathrm{~mm}$, and Length to be $120 \mathrm{~mm}$ TDFLC generates a crisp value of $12.8 \mathrm{~mm}$ for T.Deflection. For real-time simulation, a geometry of Copper-Steel bimetallic strip with dimensions of $120 \times 7 \times 1.4 \mathrm{~mm}$ is designed by ANSYS Static Structural. The initial temperature of the bimetallic strip is $22^{\circ} \mathrm{C}$. At $300{ }^{\circ} \mathrm{C}$ temperature, the bimetallic strip shows $0 \mathrm{~mm}$ deflection at the fixed support end-side while a thermal deflection of $12.8 \mathrm{~mm}$ at the free end side of the bimetallic strip. Both Fuzzy Logic and ANSYS Static Structural show the same tip deflection of $12.8 \mathrm{~mm}$ for a temperature difference of $278{ }^{\circ} \mathrm{C}$. For verification of simulations results, tip deflection is also calculated using the standard formulation of thermal deflection for a fixed-free support bimetallic beam. For Copper-Steel bimetal, using the specific deflection is $4.4 \times 10^{-6}{ }^{\circ} \mathrm{C}^{-1}$ calculated by equation 2 . For a temperature difference of $278^{\circ} \mathrm{C}$, length of $120 \mathrm{~mm}$, and thickness of $1.4 \mathrm{~mm}$ using equation 1 the tip deflection comes out to be $12.6 \mathrm{~mm}$. When the results of these simulations are compared with standard formulation results of tip deflection of bimetal both simulations show an error of $1.59 \%$; The simulation's results are in good agreement with the standard formulation results. The results of the work concluded that the tip deflection for fixed free bimetallic strips is inversely related to thickness while in direct relation with both Temperature difference and Length of bimetal. Results are shown below in table 3 .

Table 3. Comparison of Results for Tip Deflection

\begin{tabular}{|l|c|}
\hline Categories & Tip Deflection \\
\hline Formulation $(\mathrm{mm})$ & 12.6 \\
\hline Simulation $(\mathrm{mm})$ & 12.8 \\
\hline ANSYS Static Structural & 12.8 \\
\hline Error $(\mathrm{mm})$ & 0.2 \\
\hline$\%$ Error & 1.59 \\
\hline
\end{tabular}

\section{CONCLUSION}


The purpose of this work is to simulate the tip deflection of a fixed free support Copper-Steel bimetallic strip using Fuzzy Logic Controller and ANSYS Static Structural. Simulation software is used to observe the dependency of tip deflection on temperature difference, thickness, and length of bimetallic strips. For a crisp value of temperature difference of $278^{\circ} \mathrm{C}$, the thickness of 1.4 $\mathrm{mm}$ and length of $120 \mathrm{~mm}$ TDFLC generates a tip deflection of $12.8 \mathrm{~mm}$. For the same input conditions, ANSYS Static Structural also observe the same tip deflection of $12.8 \mathrm{~mm}$. In the comparison of results with standard formulation of tip deflection, both TDDLC and ANSYS generate results with a \% error of $1.59 \%$. These simulations concluded that the tip deflection for fixed free bimetallic strips is inversely related to thickness while in direct relation with both Temperature difference and Length of bimetal.

\section{REFERENCES}

[1] Y. Wang, Y. Gao, Y. Li, W. Zhai, L. Sun, and C. Zhang, "Review of preparation and application of copper-steel bimetal composites," Emerging Materials Research, vol. 8, pp. 538-551, 2019.

[2] W. J. Whitney, "An Advanced Aluminum-TinSilicon Engine Bearing Alloy and Its Performance Characteristics," SAE Technical Paper 0148-7191, 1995.

[3] W. Xu, T. Xie, H. Zhou, M. Jiao, Y. Yin, and J. $\mathrm{Yu}$, "Design for $\mathrm{Fe} / \mathrm{Cu}$ based lead-free selflubricating laminar composites," Fenmo Yejin Jishu(Powder Metallurgy Technology), vol. 29, pp. 137-141, 2011.

[4] E. R. Howard, "Thermostatic Bimetal," Engineering and Science, vol. 5, pp. 16-24, 1942.

[5] J. Barnes, R. Stephenson, M. Welland, C. Gerber, and J. Gimzewski, "Photothermal spectroscopy with femtojoule sensitivity using a micromechanical device," nature, vol. 372, pp. 79-81, 1994.

[6] S. Timoshenko, "Analysis of bi-metal thermostats," JOSA, vol. 11, pp. 233-255, 1925.

[7] M. Kratochvíl, P. Florian, I. Mazínová, and F. Hrdlička, "FEM-Aided Material Selection and Derivation of Material Indices," in Materials Science Forum, 2018, pp. 266-274.

[8] A. Kanthal, "Thermostatic bimetal handbook," ed: KANTHAL, 1996.

[9] S. Kouravand, M. Mehrban, G. Rezazadeh, and M. Sabet, "Analytical Model Studying of a Novel Tunable Capacitor Based on Bimetallic Thermal Actuator," in 2006 IEEE International Conference on Semiconductor Electronics, 2006, pp. 218-222.

[10] A. Akbarzadeh, S. Kouravand, and B. M. Imani, "Robust design of a bimetallic micro thermal sensor using Taguchi method," Journal of Optimization Theory and Applications, vol. 157, pp. 188-198, 2013.

[11] W.-H. Chu, M. Mehregany, and R. L. Mullen, "Analysis of tip deflection and force of a bimetallic cantilever microactuator," Journal of
Micromechanics and Microengineering, vol. 3, p. 4, 1993.

[12] M. A. Ismail, N. Tamchek, M. R. A. Hassan, K. D. Dambul, J. Selvaraj, N. A. Rahim, et al., "A fiber Bragg grating-bimetal temperature sensor for solar panel inverters," sensors, vol. 11, pp. 8665-8673, 2011.

[13] A. V. Rao, K. Prasad, M. Avinash, K. Nagababu, V. Manohar, P. Raju, et al., "A study on deflection of a bimetallic beam under thermal loading using finite element analysis," International Journal of Engineering and Advanced Technology, vol. 2, pp. 81-82, 2012.

[14] Z. Zhang, K. Pei, M. Sun, H. Wu, X. Yu, H. Wu, et al., "A novel solar tracking model integrated with bistable composite structures and bimetallic strips," Composite Structures, vol. 248, p. 112506, 2020.

[15] M. Kang and E. M. Yeatman, "Coupling of piezo-and pyro-electric effects in miniature thermal energy harvesters," Applied Energy, vol. 262, p. 114496, 2020.

[16] R. J. Kumar, T. Ashokkumar, and P. Sivakumar, "Comparative analysis of deflection in a bimetal," in IOP Conference Series: Materials Science and Engineering, 2021, p. 012070.

[17] M. T. Khan, "STUDY OF THERMAL DEFORMATION ANALYSIS IN AL-STEEL AND CU-STEEL BIMETAL COMPOSITES BY ANSYS STATIC STRUCTURAL," PJEST, vol. 1, p. 11, 11 May 2021 (2021).

[18] P. Liu, L. Ma, W. Jia, T. Wang, and G. Zhao, "Hot deformation behavior of a novel bimetal consisting of BTW1 and Q345R characterized by processing maps," Frontiers of Mechanical Engineering, vol. 14, pp. 489-495, 2019.

[19] M. Frătiţa, F. Popescu, K. Uzuneanu, I. Ion, and C. Angheluță, "About Structural and Thermal Analysis of Diesel Engine Piston Using Ansys Software," in IOP Conference Series: Materials Science and Engineering, 2019, p. 012041.

[20] D. Saha, P. Glanville, and E. G. Karpov, "Analysis of antichiral thermomechanical metamaterials with continuous negative thermal expansion properties," Materials, vol. 13, p. 2139, 2020.

[21] Z. Li, S. Zhang, J. Chang, F. Zhao, Y. Zhao, and J. Gao, "Simulation study on light environment performance and heat gain of applying a bimetal automatic shading device to rooms," Energy and Buildings, vol. 211, p. 109820, 2020.

[22] J. Yoo, N. J. Jones, K. Flynn, and R. Jacobs, "Development of a water level sensor using magnetostrictive materials," AIP Advances, vol. 9, p. 035119, 2019.

[23] M. Kang and E. M. Yeatman, "Thermal Energy Harvesting Using Pyroelectric and Piezoelectric Effect," in Journal of Physics: Conference Series, 2016, p. 012073.

[24] M. Kang and E. M. Yeatman, "Hybridized thermal energy harvesting mechanism," in Journal of Physics: Conference Series, 2019, p. 012038.

[25] J. Boughaleb, A. Arnaud, B. Guiffard, D. Guyomar, R. Seveno, S. Monfray, et al., 
"Coupling of PZT thin films with bimetallic strip heat engines for thermal energy harvesting," sensors, vol. 18, p. 1859, 2018.

[26] R. Han, N. Wang, Q. He, J. Wang, and X. Li, "An Energy Harvester with Temperature Threshold Triggered Cycling Generation for Thermal Event Autonomous Monitoring," Micromachines, vol. 12, p. 425, 2021.

[27] A. M. Khatkhate and A. Danpurwala, "Simulation Studies of a Novel Formula for Predicting the Radius of Curvature of a Bimetallic Strip," i-Manager's Journal on Material Science, vol. 8, p. 17, 2020.

[28] D. Gönczi, "ANALYSIS OF A CURVED BIMETALLIC BEAM," Journal of Computational and Applied Mechanics, vol. 14, pp. 41-51, 2019.

[29] Z. Rahman, M. M. Khir, and M. Zakariya, "Tip Deflection of a Thermal Bimorph Cantilever Beam with Different Geometrical Structures," in 2018 IEEE International Conference on Semiconductor Electronics (ICSE), 2018, pp. 81-84.

[30] T. Gebrael, A. Kanj, D. Farhat, M. Shehadeh, and I. Lakkis, "Self sustained thermally induced gas-damped oscillations of bimetal cantilevers with application to the design of a new pyroelectric micro energy harvester," Journal of Physics D: Applied Physics, vol. 53, p. 195501, 2020.

[31] M. J. Afzal, M. W. Ashraf, S. Tayyaba, A. H. Jalbani, and F. Javaid, "Computer Simulation Based Optimization of Aspect Ratio for Micro and Nanochannels," Mehran University Research Journal of Engineering and Technology, vol. 39, pp. 779-791, 2020.

[32] M. J. Afzal, M. W. Ashraf, S. Tayyaba, M. K. Hossain, and N. Afzulpurkar, "Sinusoidal Microchannel with Descending Curves for Varicose Veins Implantation," Micromachines, vol. 9, p. 59, 2018.

[33] M. J. Afzal, J. Farah, S. TAYYABA, M. W. Ashraf, M. ASHIQ, and A. AKHTAR, "Simulation of a Nanoneedle for Drug Delivery by Using MATLAB Fuzzy Logic," Biologia, vol. 64, p. 9, 2018.

[34] M. J. Afzal, F. Javaid, S. Tayyaba, M. W. Ashraf, and M. K. Hossain, "Study on the Induced Voltage in Piezoelectric Smart Material (PZT) Using ANSYS Electric \& Fuzzy Logic," 2020.

[35] M. J. Afzal, F. Javaid, S. Tayyaba, M. W. Ashraf, C. Punyasai, and N. Afzulpurkar, "Study of Charging the Smart Phone by Human Movements by Using MATLAB Fuzzy Technique," in 2018 15th International Conference on Electrical Engineering/Electronics, Computer, Telecommunications and Information Technology (ECTI-CON), 2018, pp. 411-414.

[36] M. J. Afzal, F. Javaid, S. Tayyaba, M. W. Ashraf, and M. I. Yasin, "Study of Constricted Blood Vessels through ANSYS Fluent," Biologia, vol. 66 (II), pp. 197-201, 2020.
[37] M. J. Afzal, F. Javaid, S. Tayyaba, A. Sabah, and M. W. Ashraf, "Fluidic simulation for blood flow in five curved Spiral Microchannel," Biologia, vol. 65, p. 141, 2019.

[38] M. J. Afzal, S. Tayyaba, M. W. Ashraf, M. K. Hossain, and N. Afzulpurkar, "Fluidic simulation and analysis of spiral, U-shape and curvilinear nano channels for biomedical application," in 2017 IEEE International Conference on Manipulation, Manufacturing and Measurement on the Nanoscale (3MNANO), 2017, pp. 190-194.

[39] M. J. Afzal, S. Tayyaba, M. W. Ashraf, M. K. Hossain, M. J. Uddin, and N. Afzulpurkar, "Simulation, fabrication and analysis of silver based ascending sinusoidal microchannel (ASMC) for implant of varicose veins," Micromachines, vol. 8, p. 278, 2017.

[40] M. J. Afzal, S. Tayyaba, M. W. Ashraf, and G. Sarwar, "Simulation of fuzzy based flow controller in ascending sinusoidal microchannels," in 2016 2nd International Conference on Robotics and Artificial Intelligence (ICRAI), 2016, pp. 141-146.

[41] J. Farah and S. Said, "FUZZY SIMULATION OF DRUG DELIVERY SYSTEM THROUGH VALVE-LESS MICROPUMP," PJEST, vol. 1, p. 9, 27 April 2021.

[42] S. Tayyaba, M. J. Afzal, G. Sarwar, M. W. Ashraf, and N. Afzulpurkar, "Simulation of flow control in straight microchannels using fuzzy logic," in 2016 International Conference on Computing, Electronic and Electrical Engineering (ICE Cube), 2016, pp. 213-216. 